\title{
A Biologically Active Surface Enzyme Assembly that Attenuates Thrombus Formation
}

\author{
Zheng Qu, Sharmila Muthukrishnan, Murali K. Urlam, Carolyn A. Haller, \\ Sumanas W. Jordan, Vivek A. Kumar, Ulla M. Marzec, Yaseen Elkasabi, \\ Joerg Lahann, Stephen R. Hanson, and Elliot L. Chaikof*
}

Activation of hemostatic pathways by blood-contacting materials remains a major hurdle in the development of clinically durable artificial organs and implantable devices. Here, it is postulated that surface-induced thrombosis may be attenuated by the reconstitution onto blood contacting surfaces of bioactive enzymes that regulate the production of thrombin, a central mediator of both coagulation and platelet activation cascades. Thrombomodulin (TM), a transmembrane protein expressed by endothelial cells, is an established negative regulator of thrombin generation in the circulatory system. Traditional techniques to covalently immobilize enzymes on solid supports may modify residues contained within or near the catalytic site, thus reducing the bioactivity of surface enzyme assemblies. In this report, a molecular engineering and bioorthogonal chemistry approach to site-specifically immobilize a biologically active recombinant human TM fragment onto the luminal surface of small diameter prosthetic vascular grafts is presented. Bioactivity and biostability of TM modified grafts is confirmed in vitro and the capacity of modified grafts to reduce platelet activation is demonstrated using a non-human primate model. These studies indicate that molecularly engineered interfaces that display TM actively limit surface-induced thrombus formation.

\section{Introduction}

The molecular engineering of biologically active surface assemblies that control host reactions at tissue-material interfaces may be an important step in the development of clinically durable artificial organs and implantable devices. ${ }^{[1,2]}$ In this regard, pathological thrombus formation on materials in direct contact with blood has precluded development of a clinically durable small-diameter $(<5 \mathrm{~mm}$ inner diameter) arterial prosthesis critical to the fields of cardiac, vascular, and plastic surgery, and has necessitated adjunctive antithrombotic therapies that increase bleeding risk and healthcare costs for numerous cardiovascular procedures. ${ }^{[3,4]}$ The onset and amplification of thrombogenesis on blood-contacting materials involves concomitant activation of platelets and elaboration of the coagulation cascade to generate thrombin and fibrin, culminating in hemostatic plug formation..$^{[5]}$ Thrombin serves as a central initiator, amplifier, and effector molecule at the nexus of these

Dr. C. A. Haller, Prof. E. L. Chaikof

Department of Surgery

Beth Israel Deaconess Medical Center

Harvard Medical School,

and the Wyss Institute of Biologically Inspired

Engineering of Harvard University

Boston, MA 02115, USA

E-mail: echaikof@bidmc.harvard.edu

Z. Qu, Dr. S. Muthukrishnan, Dr. M. K. Urlam,

Dr. S. W. Jordan, V. A. Kumar

Departments of Biomedical Engineering and Surgery

Georgia Institute of Technology and Emory University

Atlanta, GA 30322, USA

U. M. Marzec, Prof. S. R. Hanson

Oregon National Primate Research Center

Oregon Health and Science University

Beaverton, OR 97006, USA

Dr. Y. Elkasabi, Prof. J. Lahann

Department of Chemical Engineering

University of Michigan

Ann Arbor, MI 48109, USA

DOI: $10.1002 / \mathrm{adfm} .201101687$ pathways by crosslinking fibrin, directly triggering platelet activation that leads to a local burst of thrombin production, ${ }^{[6]}$ and eliciting inflammatory reactions ${ }^{[7]}$ that influence long-term healing characteristics of implanted materials. ${ }^{[8]}$ Therefore, a rational approach to improve blood compatibility and long-term durability of blood-contacting materials may entail the incorporation of endogenous regulators of thrombin production, normally active within the endothelial cell membrane, onto synthetic molecularly engineered surfaces.

Heparan sulfate proteoglycans (HSPG) in the arterial wall accelerates thrombin inactivation by antithrombin III, a mechanism Gott and coworkers first replicated on artificial surfaces by heparin immobilization in $1963 .{ }^{[9]}$ However, the physiological significance of HSPG remains poorly understood, since the majority of anticoagulantly active HSPG is not in direct contact with flowing blood, ${ }^{[10]}$ and thrombin becomes resistant to inhibition by the heparin-antithrombin III complex upon binding to fibrin. ${ }^{[11]}$ Alternatively, surface-bound direct thrombin inhibitors, such as hirudin ${ }^{[12-15]}$ and its analogues, ${ }^{[16]}$ as well as argatroban, ${ }^{[17,18]}$ and benzamidine ${ }^{[19]}$ quench the activity of locally 


\section{ePTFE}
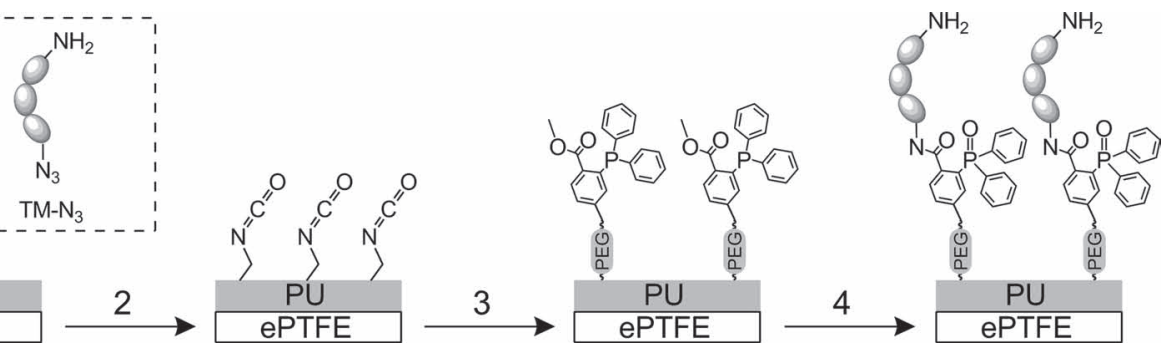

Scheme 1. Reaction sequence to covalently immobilize recombinant human thrombomodulin (TM) onto the luminal surface of expanded poly(tetrafluoroethylene) (ePTFE) grafts: (1) generation of polyurethane (PU) coating on ePTFE graft lumen; (2) isocyanate activation of PU with hexamethylene diisocyanate; (3) immobilization of amino- $\mathrm{PEG}_{11}$-triphenylphosphine $\left(\mathrm{NH}_{2}-\mathrm{PEG}_{11}-\mathrm{TPP}\right)$ linker; (4) Staudinger Ligation of recombinant TM expressing a single C-terminal azide moiety $\left(\mathrm{TM}-\mathrm{N}_{3}\right)$ to TPP.

produced thrombin. However, a potential constraint of these approaches is the inability to generate a continuous surface reservoir of direct thrombin inhibitors that would be required to curtail self-reinforcing thrombin generation cascades which are rapidly amplified upon initiation. Hemostatic occlusion in the arterial circulation is actively regulated by the protein $\mathrm{C}(\mathrm{PC})$ pathway, whereby activated protein $\mathrm{C}(\mathrm{aPC})$ inactivates precursors requisite for amplification of coagulation and thrombin formation. ${ }^{[20]}$ Endothelial cells that line the vascular system express thrombomodulin (TM), a transmembrane protein that binds thrombin as a 1:1 stoichiometric complex. In the process of sequestering thrombin, TM limits its capacity to activate platelets or to otherwise serve as a prothrombotic factor. More importantly, TM accelerates thrombin's ability to produce aPC by 1000 -fold. ${ }^{[21]}$ Hence, we postulate that engineering blood-contacting surfaces which display biologically active TM assemblies would locally generate aPC "on demand", thereby, inhibiting thrombin generation.

Traditional techniques to immobilize active enzymes on solid supports, such as passive adsorption or covalent ligation via free amino or carboxyl residues ${ }^{[22]}$ have been reported to generate surfaces modified with TM. ${ }^{[23-30]}$ However, these covalent ligation approaches randomly orient immobilized enzymes and potentially modify residues contained within or near the catalytic site, ${ }^{[31]}$ consequently reducing optimal surface activity that could otherwise be achieved by these enzyme assemblies. Emerging advances in bioorthogonal chemistry and molecular engineering provide an opportunity to site-specifically tether large enzymes onto surfaces. The azide $\left(-\mathrm{N}_{3}\right)$ group is absent from biological systems and was first explored as a bioorthogonal handle with Staudinger Ligation. ${ }^{[32]}$ Further application of this chemistry to immobilize proteins containing an azidemodified $\mathrm{C}$ terminus has been performed on glass surfaces modified with triphenylphosphine, ${ }^{[33,34]}$ but thiol reagents used in expressed protein ligation to generate the azide moiety may perturb the folding and catalytic activity of bioenzymes rich in disulfide bonds, ${ }^{[35]}$ including TM. ${ }^{[36]}$ An alternative strategy that first converted a single lysine residue to azide facilitated immobilization of an active enzyme by traceless Staudinger Ligation on glass, which maximized its bioactivity relative to random coupling via amine residues. ${ }^{[37]}$ However, a possible limitation of this approach is the lack of site-specificity when multiple lysines are present in larger biomolecules, such as TM.

Our laboratory has generated a truncated $15 \mathrm{kDa}$ human TM fragment containing the soluble extracellular epidermal growth factor-like domains 4 through $6\left(\mathrm{EGF}_{4-6}\right),{ }^{[38]}$ which displays the requisite binding sites for thrombin and protein $\mathrm{C}$ necessary to catalyze production of aPC. ${ }^{[39]}$ Using site-specific incorporation of the non-canonical methionine surrogate azidohomoalanine, ${ }^{[40]}$ we have generated a TM variant expressing a single C-terminal azide moiety $\left(\mathrm{TM}-\mathrm{N}_{3}\right)$. In this report, we immobilize recombinant $\mathrm{TM}-\mathrm{N}_{3}$ by Staudinger Ligation onto the luminal surface of polyurethane coated expanded poly(tetrafluoroethylene) (ePTFE) vascular grafts (Scheme 1). Further, we demonstrate the capacity of these surfaces to generate aPC and confirm the stability of TM surface assemblies in vitro. The ability of TM modified grafts to inhibit thrombosis in vivo was demonstrated using a non-human primate model.

\section{Results and Discussion}

\subsection{Coating of ePTFE Grafts with a Polyurethane Film}

Although inert PTFE surfaces may be modified by high energy radiation to generate reactive chemical handles, ${ }^{[41]}$ translation of these techniques to ePTFE vascular prostheses on clinically relevant length scales has been difficult. Therefore, an extrusion method was used to deposit a thin coating of medical grade Elasthane $80 \mathrm{~A}$ polyurethane (PU) onto the luminal surface of ePTFE grafts that could then be readily modified by chemical techniques. ${ }^{[42]}$ Scanning electron microscopy (SEM) confirmed deposition of a smooth, uniform $\sim 50 \mu \mathrm{m}$ PU film that penetrated the porous node-fibril architecture of ePTFE (Figure 1). As expected, PU coating thickness was proportional to the quantity of material deposited and uniform along the length of the prosthesis (Figure 2). Attenuated total reflectance IR (ATR-IR) spectroscopy was performed on PU coatings on ePTFE (Figure 3a), as well as model thin films generated by solvent casting of PU onto glass substrates (Figure 3b). Characteristic of PU a hydrogen-bonded urethane $\mathrm{N}-\mathrm{H}$ peak at $3320 \mathrm{~cm}^{-1}$ was observed, as were peaks at 2885 and $1535 \mathrm{~cm}^{-1}$ corresponding to $\mathrm{C}-\mathrm{H}$ stretching and $\mathrm{C}-\mathrm{H}-\mathrm{N}$ bending, respectively. Additional PU peaks were detected at $1591 \mathrm{~cm}^{-1} \quad\left(\mathrm{C}=\mathrm{C}\right.$, aromatic ring), $1110 \mathrm{~cm}^{-1}$ (C-O-C, stretch), $1730 \mathrm{~cm}^{-1}$ (urethane $\mathrm{C}=\mathrm{O}$, free from hydrogen bonding), and $1710 \mathrm{~cm}^{-1}$ (urethane $\mathrm{C}=\mathrm{O}$, hydrogen bonded), consistent with prior reports. ${ }^{[43]}$ 

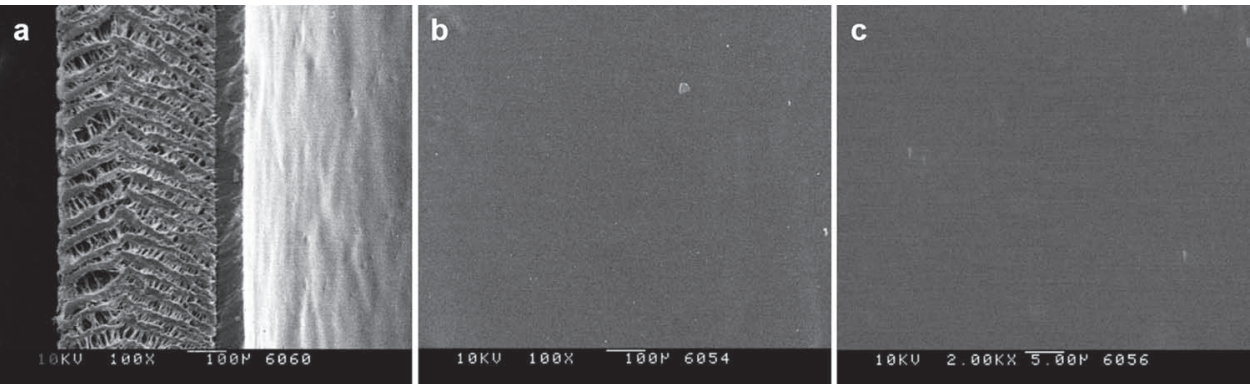

Figure 1. Scanning electron microscopy of polyurethane (PU) coating on (a) the edge of ePTFE graft at 100x, and on (b) the luminal surface at 100x and (c) 2000x. Scale bars: a,b) $100 \mu \mathrm{m}$; (c) $5 \mu \mathrm{m}$.
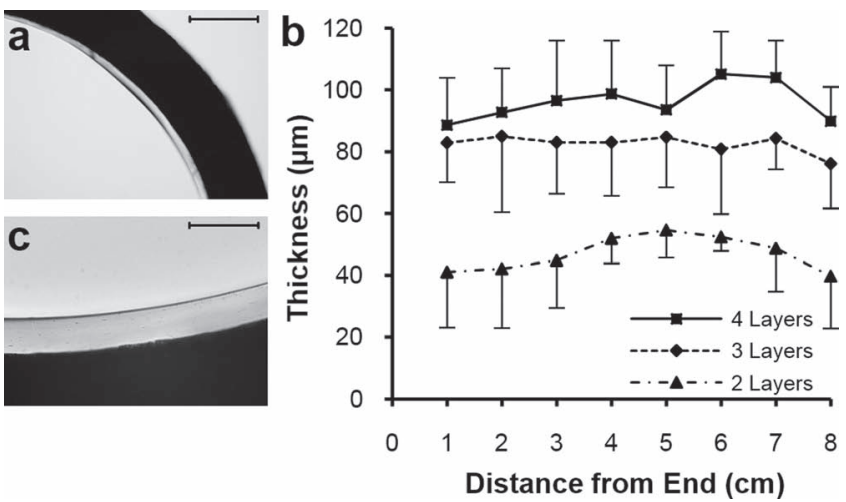

Figure 2. Light microscopy of thin cross sections of polyurethane (PU) coated ePTFE grafts. (a) Interface between opaque ePTFE graft wall and transparent 2-layer PU lining observed at $4 \times$. (b) Mean \pm standard deviation of PU thickness measured at 4 positions per cross section and $1 \mathrm{~cm}$ intervals along $8 \mathrm{~cm}$ ePTFE graft segment coated with 2, 3, and 4 deposited layers of PU on top of a base extruded layer. (c) Interface between opaque ePTFE graft wall and transparent 4 layer PU lining observed at 20x. Scale bars: (a) $500 \mu \mathrm{m}$; (c) $100 \mu \mathrm{m}$.

\subsection{Chemical Modification of ePTFE Grafts}

Amine-reactive isocyanate groups were generated on PU coated grafts using a rotary reactor, which facilitated uniform mixing of reagents (Figure 4). ${ }^{[44]}$ PU coated grafts were incubated for $1 \mathrm{~h}$ with hexamethylene diisocyanate (HDI) in the presence of triethylamine (TEA) at $50{ }^{\circ} \mathrm{C}$, as demonstrated elsewhere. ${ }^{[45]}$ ATR-IR spectroscopy detected a distinct peak at $2260 \mathrm{~cm}^{-1}$ corresponding to $-\mathrm{N}=\mathrm{C}=\mathrm{O}$ (Figure 3). A heterobifunctional linker comprised of a poly(ethylene glycol) (PEG) spacer with amino $\left(-\mathrm{NH}_{2}\right)$ and triphenylphosphine (TPP) end groups ( $\left.\mathrm{NH}_{2}-\mathrm{PEG}_{11}-\mathrm{TPP}\right)$ was used to derivatize accessible surface isocyanates (Scheme 1), as confirmed by loss of the $-\mathrm{N}=\mathrm{C}=\mathrm{O}$ peak by ATR spectroscopy (Figure 3). Consistent with this finding, X-ray photoelectron spectroscopy (XPS) revealed a sharp decrease in the $\mathrm{C}(285 \mathrm{eV})$ to $\mathrm{O}(532 \mathrm{eV})$ ratio (Figure $5 \mathrm{a}-\mathrm{c}$ and Table 1) and the presence of distinct phosphorous peaks (P $2 p$ at $133 \mathrm{eV}$ and $\mathrm{P} 2 \mathrm{~s}$ at $200 \mathrm{eV}$ ) (Figure 5c). The absence of fluorine peaks (Figure $5 \mathrm{a}-\mathrm{c}$ ) further confirmed complete coverage of ePTFE by the PU thin film. High resolution C 1 s XPS (Figure $5 \mathrm{~d}-\mathrm{f}$ and Table 1) revealed a dramatic increase in $\mathrm{N}-\mathrm{C}=\mathrm{O}(289.0 \mathrm{eV})$ intensity and increased ether carbon content $(\mathrm{C}-\mathrm{O}, 286.4 \mathrm{eV})$ after immobilization of the PEG linker. These observations confirm the initial generation of reactive isocyanates followed by the display of TPP moieties on the luminal surface of PU-coated ePTFE grafts.

\subsection{Staudinger Ligation of Azide Probe on ePTFE}

A fluorescent azide probe was used to initially assess the specificity of small molecule immobilization by Staudinger Ligation. ${ }^{46]}$

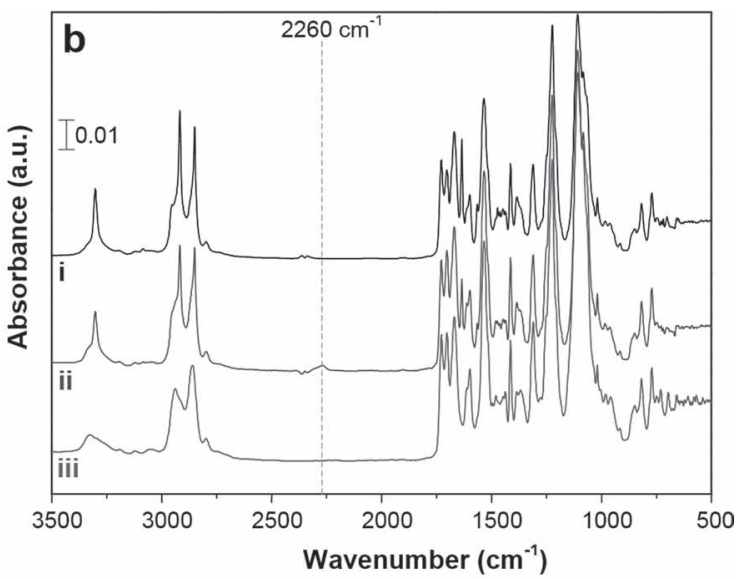

Figure 3. Attenuated reflection infrared spectroscopy of (a) polyurethane (PU) coated on the luminal surface of ePTFE grafts and (b) thin solvent cast PU films. Representative spectra given for (i) PU, (ii) PU subjected to isocyanate activation with hexamethylene diisocyanate, and (iii) PU modified with a heterobifunctional $\mathrm{NH}_{2}-\mathrm{PEG}_{11}$-triphenylphosphine linker. 

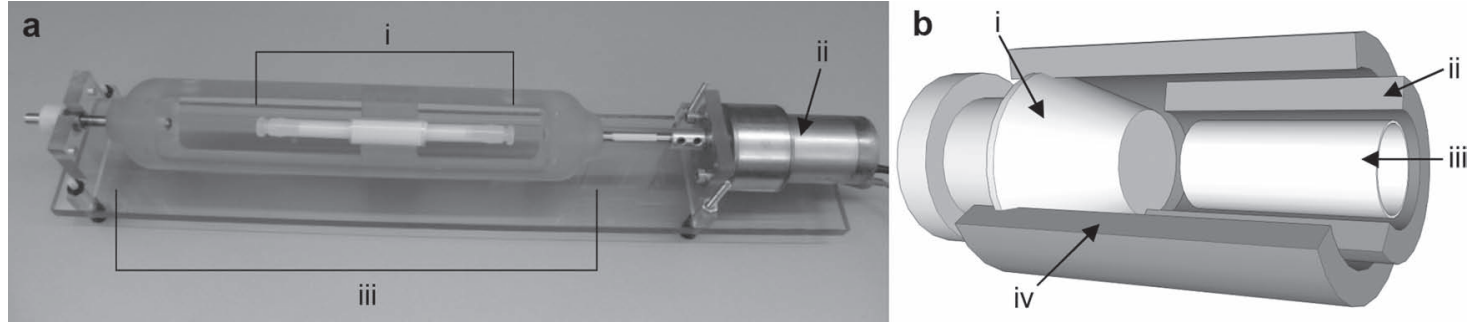

Figure 4. Reactor setup for chemical derivatization of PU modified ePTFE grafts. (a) $4 \mathrm{~mm}$ i.d. ePTFE grafts were chemically modified using a custom reactor design comprising (i) reactor housing for ePTFE graft and a (ii) DC motor that is coupled to a (iii) form-fitting rotator clamp for graft reactors to facilitate rotation along the axial length of grafts. (b) Inner construction of reactor housing for ePTFE graft comprising (i) barbed Kynar plugs to seal both ends of tubular reaction vessel; (ii) inner $5 \mathrm{~mm}$ i.d., $7 \mathrm{~mm}$ o.d. Teflon tube; (iii) $4 \mathrm{~mm}$ i.d. ePTFE graft; (iv) outer $7 \mathrm{~mm}$ i.d., $9 \mathrm{~mm}$ o.d. Teflon tube.

Rhodamine $\mathrm{B}$ and its azide analogue tetramethylrhodamine 5-carbonyl azide $\left(\mathrm{Rh}-\mathrm{N}_{3}\right)$ were reacted in parallel with PU films functionalized with TPP. Following extensive rinsing in methanol, it was evident that only $\mathrm{Rh}-\mathrm{N}_{3}$ was covalently immobilized to TPP modified PU films (Figure 6a). This result was semiquantitatively corroborated by UV-Vis spectroscopy (Figure 6b), and verified visually on PU-coated ePTFE grafts (Figure 6c).

\subsection{Immobilization of Thrombomodulin}

TPP modified grafts were exposed to recombinant TM expressing either a single C-terminal azide moiety $\left(\mathrm{TM}-\mathrm{N}_{3}\right)$ or a native methionine (TM-methionine). Following a phosphate buffered saline (PBS, $\mathrm{pH} 7.4$ ) rinse for $24 \mathrm{~h}$, the capacity to activate $\mathrm{PC}$ was assessed in vitro. Grafts reacted with $\mathrm{TM}-\mathrm{N}_{3}$ afforded a 30-fold increase in their capacity to activate aPC as compared to grafts incubated with TM-methionine ( $0.4 \mathrm{vs} \sim 12 \mathrm{ng}$ aPC $\mathrm{cm}^{-2} \mathrm{~min}^{-1}, \mathrm{p}<0.01$; Figure $\left.7 \mathrm{a}\right)$. The density of covalently bound TM was measured using a horseradish peroxidase (HRP) conjugated antibody that recognizes the human TM $\mathrm{EGF}_{5,6}$ domain. Surface density of TM-N $\mathrm{N}_{3}$ was $\sim 170 \mathrm{fmol} / \mathrm{cm}^{2}$ after subtracting background binding of antibody to unmodified PU (Figure 7b). ${ }^{[4]}$ The aPC generating capacity reported herein is greater than that previously reported for random immobilization strategies. ${ }^{[34,37]}$ Since the minimum aPC flux required to
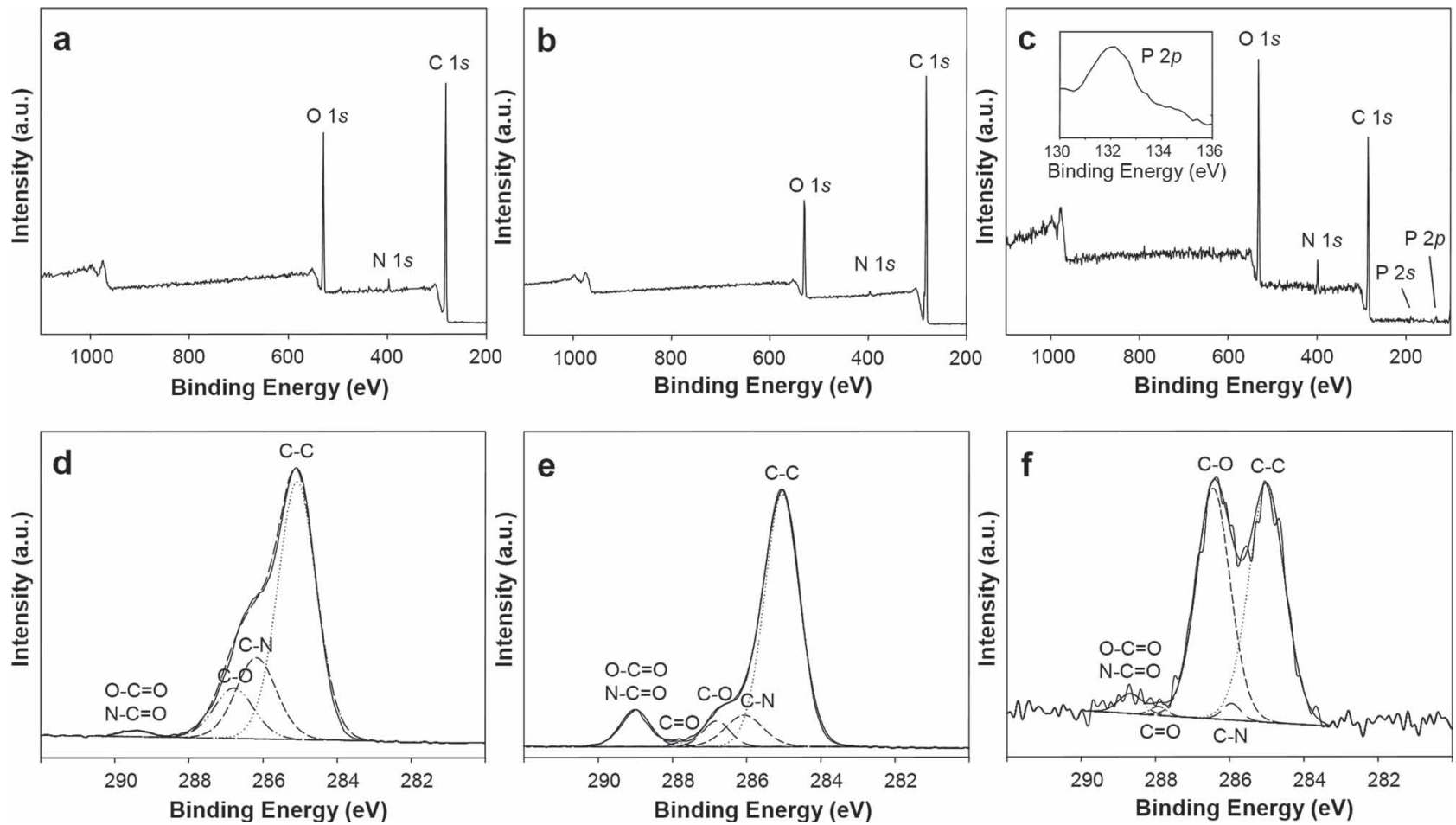

Figure 5. Survey and high resolution X-ray photoelectron spectroscopy (XPS) of PU modified ePTFE grafts. Survey XPS were performed on the ePTFE graft lumen following (a) surface coating with PU, (b) subsequent isocyanate modification, and (c) $\mathrm{NH}_{2}-\mathrm{PEG}_{11}-\mathrm{TPP}$ linker immobilization. Corresponding high resolution C 1s XPS were performed on the ePTFE graft lumen following (d) surface coating with PU, (e) subsequent isocyanate modification, and (f) $\mathrm{NH}_{2}-\mathrm{PEG}_{11}$-TPP linker immobilization. 
Table 1. Elemental analysis of modified ePTFE grafts by XPS.

\begin{tabular}{|c|c|c|c|c|c|c|c|}
\hline \multirow[b]{2}{*}{ Substrate } & \multicolumn{4}{|c|}{ Survey XPS } & \multicolumn{3}{|c|}{ High Resolution C 1s XPS } \\
\hline & C [\%] & $\mathrm{O}[\%]$ & $\mathrm{N}[\%]$ & C/O Ratio & $\mathrm{C}-\mathrm{C}[\%]$ & $\mathrm{C}-\mathrm{O}[\%]$ & $\mathrm{O}-\mathrm{C}=\mathrm{O} \mathrm{N}-\mathrm{C}=\mathrm{O}[\%]$ \\
\hline$P U^{a)}$ & 81 & 17 & 1.6 & 4.8 & 65 & 13 & 1.1 \\
\hline $\mathrm{PU}-\mathrm{NCO}^{\mathrm{b}}$ & 86 & 13 & 0.70 & 6.6 & 74 & 6.0 & 9.2 \\
\hline PU-TPPc) & 70 & 24 & 4.6 & 2.9 & 50 & 45 & 2.8 \\
\hline
\end{tabular}

a) Bare polyurethane (PU); ${ }^{\text {b) }}$ isocyanate activated $\mathrm{PU}$; ${ }^{\mathrm{c}} \mathrm{PU}-\mathrm{NCO}$ reacted with $\mathrm{NH}_{2}-\mathrm{PEG}_{11}-\mathrm{TPP}$ linker.
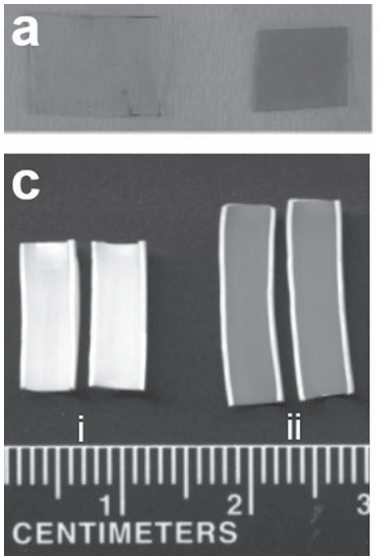

\section{b}

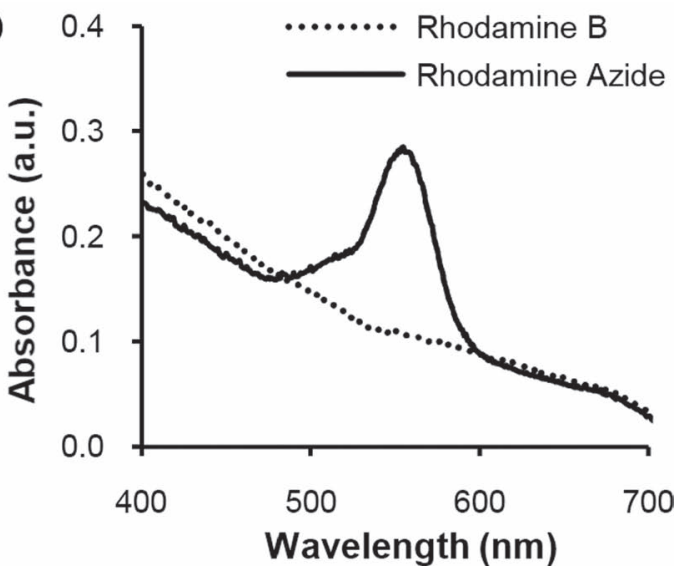

as to an additional 2 week period in PBS at $37^{\circ} \mathrm{C}$. Catalytic activity remained nearly constant indicating that covalently immobilized TM- $\mathrm{N}_{3}$ was unaffected by short-term exposure to arterial shear, as well as extended incubation under physiologically relevant $\mathrm{pH}$ and temperature conditions (Figure 7c). Notably, random amine-crosslinking techniques used to immobilize TM on ePTFE resulted in a $50 \%$ reduction in surface activity following exposure to mechanical shear for 7 hours at $37^{\circ} \mathrm{C} \cdot{ }^{[27]}$ Others have reported a $\sim 30 \%$ reduction in activity when TM modified surfaces were subjected to static incubation in PBS at $37^{\circ} \mathrm{C}$ for 4 weeks. ${ }^{[29]}$

Figure 6. Feasibility of immobilizing azide probes by Staudinger Ligation on polyurethane films. (a) Visual confirmation of solvent cast PU films derivatized with TPP and reacted with either (left) rhodamine B or (right) rhodamine azide. (b) Solvent cast thin PU films activated with TPP anchor groups were reacted with either rhodamine B or rhodamine azide and analyzed by UV-Vis spectroscopy. (c) En face examination of TPP modified grafts following reaction with (i) rhodamine $\mathrm{B}$ or (ii) rhodamine azide and rinsing with methanol.

inhibit thrombosis has not been established, predicting in vivo performance is not feasible.

Biostability was assessed by subjecting TM-modified grafts to PBS at a shear rate of $500 \mathrm{~s}^{-1}$ and $37^{\circ} \mathrm{C}$ for $24 \mathrm{~h}$, as well bogenicity of blood contacting materials under dynamic arterial flow conditions, particularly when implanted in sub-human primates, such as the baboon, whose hemostatic system closely resembles that of man. ${ }^{[48-51]}$ Platelet binding to PU coated
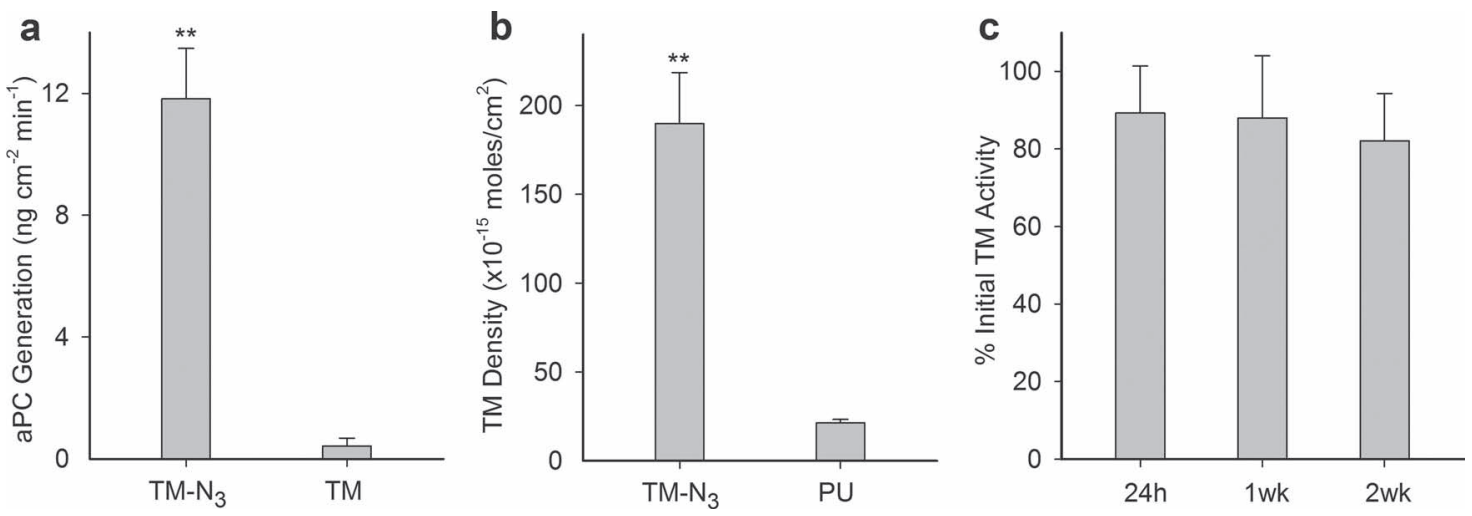

Figure 7. Measurement of thrombomodulin (TM) cofactor activity to generate aPC, TM surface density, and stability of immobilized TM on modified ePTFE grafts. (a) Catalytic activity of TPP modified ePTFE grafts reacted with recombinant TM expressing a C-terminal azide moiety (TM-N ${ }_{3}$ ) or TM containing its native C-terminal methionine. (b) Surface density of TM on grafts was quantified using a TM antibody and compared with background binding of antibody to bare PU coated ePTFE. (c) Graft activity measured as a percentage of initial levels following $24 \mathrm{~h}$ of mechanical shear at $500 \mathrm{~s}^{-1}$ at $37^{\circ} \mathrm{C}$ and subsequent 2-week incubation in PBS at $37^{\circ} \mathrm{C}$. Data represents mean \pm standard deviation for $\mathrm{n} \geq 3$ samples. Statistical difference $(p<0.01)$ versus control is denoted by a double asterisk. 
a

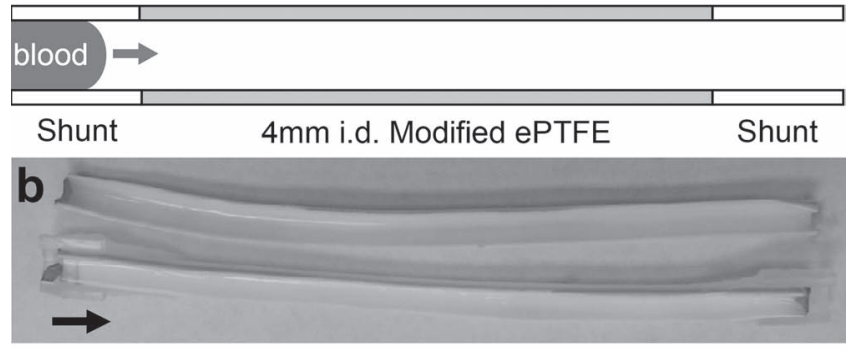

C

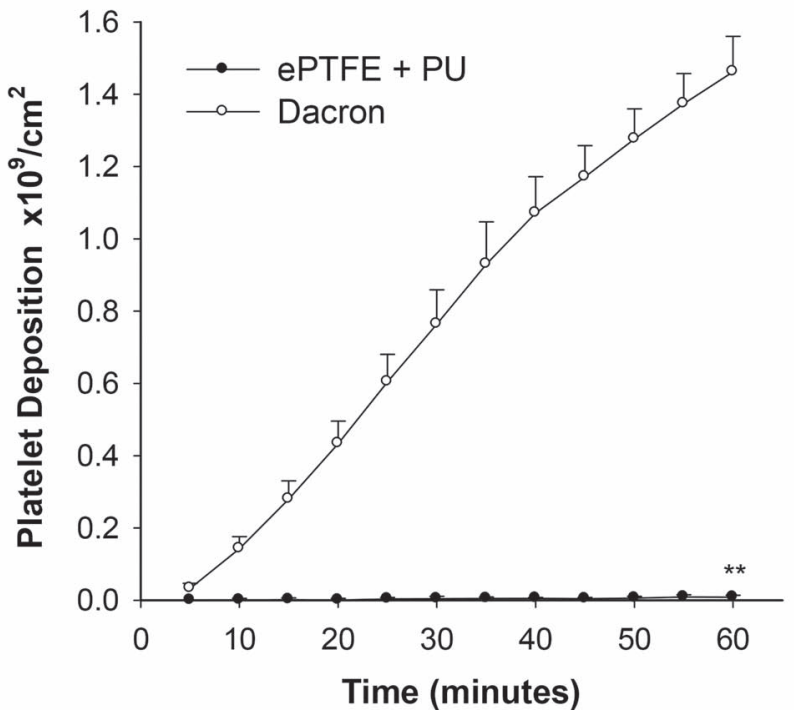

Figure 8. Real time platelet deposition on modified ePTFE grafts in the absence of an upstream thrombus source in the baboon shunt model. (a) Shunt configuration for testing thrombogenicity of $4 \mathrm{~mm}$ i.d. tubular materials. (b) Representative photo of a $7 \mathrm{~cm}$ length bare PU coated ePTFE graft split in half lengthwise following $1 \mathrm{~h}$ perfusion at $100 \mathrm{~mL} / \mathrm{min}$; Arrow points in direction of blood flow. (c) Comparison of platelet deposition on bare PU coated $4 \mathrm{~mm}$ i.d. ePTFE (ePTFE + PU) with plain $4 \mathrm{~mm}$ i.d. Dacron grafts. Each data point represents mean \pm standard deviation for $n \geq 3$ samples. Statistical difference $(p<0.01)$ is denoted by double asterisk.

PTFE grafts (4 mm i.d.) was assessed using an arteriovenous perfusion chamber and compared to responses observed to unmodified Dacron grafts (Figure 8). ${ }^{[49,52]}$ Cumulative platelet deposition on PU coated ePTFE was substantially lower than on Dacron grafts $\left(0.0082\right.$ vs 1.5 billion $\left./ \mathrm{cm}^{2}\right)$. Since the level of platelet deposition on PU coated ePTFE grafts is too low to gauge the therapeutic efficacy of immobilized TM, we explored thrombus growth in a perfusion system in which a test graft was interposed between a collagen coated ePTFE graft, as a thrombogenic source, and a distal expansion chamber (Figure 9). ${ }^{[48,49]}$ TM modified ePTFE grafts reduced platelet deposition in the distal expansion chamber by nearly $50 \%$ when compared to unmodified PU coated grafts $(\mathrm{n}=4, \mathrm{p}<0.05)$. Since thrombin is an important physiological agonist for platelet activation, ${ }^{[6]}$ the measured reduction of platelet deposition in the distal expansion chamber suggests that substantial levels of aPC are generated from the TM modified surface. In addition to attenuating thrombosis, local generation of aPC may influence the healing characteristics of implanted grafts, as late prosthetic graft failure has been attributed to progressive intimal hyperplasia, a process exacerbated by thrombin and platelet derived pro-inflammatory factors. ${ }^{[7,53]}$

\section{Conclusions}

We have presented a biomimetic surface engineering approach that combines molecular engineering and orthogonal chemistry strategies to site-specifically functionalize clinical vascular prostheses with recombinant human TM that exhibit biocatalytic activity and biostability in vitro. Moreover, we have devised and tested a robust, clinically relevant in vivo model of vascular graft thrombosis in non-human primates that facilitated evaluation of the therapeutic function of bioactive TM surface assemblies. The data presented herein indicate that a biologically active TM surface assembly reduces the thrombogenic properties of blood contacting surfaces despite the presence of an upstream thrombin generating stimulus. The modular nature of heterobifunctional linker design, combined with recent advances in chemoselective techniques to modify peptides and proteins, ${ }^{[54,55]}$ will undoubtedly expand the utility of bioenzyme surface assemblies to a range of clinically important host-material interfaces.

\section{Experimental Section}

Reagents: All reagents were purchased from Sigma-Aldrich, St Louis and used without further purification unless otherwise noted. Expression and purification of recombinant TM-methionine and TM- $\mathrm{N}_{3}$ are detailed elsewhere ${ }^{[38]}$.

Synthesis of $\mathrm{NH}_{2}-P E G_{11}-T P P: \mathrm{NH}_{2}-\mathrm{PEG}_{11}-\mathrm{TPP}$ was synthesized by reaction of $O$-(2-aminoethyl)- $O^{\prime}$-[2-(Boc-amino)ethyl]decaethylene glycol with a pentafluorophenyl ester of TPP[46] in $\mathrm{CH}_{2} \mathrm{Cl}_{2}$ and 3 equiv 2,6-lutidine at $25^{\circ} \mathrm{C}$ for $12 \mathrm{~h}$, followed by removal of Boc using $\mathrm{CF}_{3} \mathrm{COOH}$ and purification by column chromatography. ${ }^{1} \mathrm{H} N \mathrm{NMR}$ $\left(400 \mathrm{MHz}, \mathrm{CDCl}_{3}\right): \delta 8.10$ (dd, $\left.1 \mathrm{H}, \mathrm{J}=3.6,8\right), 7.83$ (dd, $1 \mathrm{H}, \mathrm{J}=1.6$, 8.4), 7.39-7.28 (m, 11H), $6.81(\mathrm{~m}, 1 \mathrm{H}), 3.80$ (brs, $2 \mathrm{H}), 3.76(\mathrm{~s}, 3 \mathrm{H})$, 3.70-3.49 (m, 46H), $2.97(\mathrm{t}, 2 \mathrm{H}, J=5.2)$; HRMS (ESI, $m / z)$ : $[\mathrm{M}+\mathrm{H}]^{+}$calcd for $\mathrm{C}_{45} \mathrm{H}_{68} \mathrm{~N}_{2} \mathrm{O}_{14} \mathrm{P}, 891.4408$; found, 891.4396 .

Modification of ePTFE Grafts: $5 \%$ w/v Elasthane 80A (Polymer Tech, Berkeley) in $\mathrm{N}, \mathrm{N}$-dimethylformamide (DMF) was extravasated through $4 \mathrm{~mm}$ i.d. ePTFE thin wall vascular grafts (Bard, Tempe) and dried under vacuum at $60{ }^{\circ} \mathrm{C}$ for $20 \mathrm{~min}$. Additional PU was deposited in multiple flow-through/drying cycles over the base layer, and dried overnight under vacuum at $60^{\circ} \mathrm{C}$. PU coated grafts were inserted into tubular reactors as depicted in Figure 4 and rotated at $500 \mathrm{rpm}$ for surface reactions. Grafts were first reacted with $\mathrm{HDI}(16 \% \mathrm{v} / \mathrm{v})$ and TEA $(4 \% \mathrm{v} / \mathrm{v})$ in toluene at $50{ }^{\circ} \mathrm{C}$ for $1 \mathrm{~h}$ and rinsed in toluene for $6 \mathrm{~h}$. Isocyanate activated grafts were reacted with $\mathrm{NH}_{2}-\mathrm{PEG}_{11}-\mathrm{TPP}$ linker $(10 \mathrm{mg} / \mathrm{mL})$ and TEA $(1 \% \mathrm{v} / \mathrm{v})$ in toluene at $40{ }^{\circ} \mathrm{C}$ overnight, rinsed with toluene for $6 \mathrm{~h}$, and dried under vacuum at $25{ }^{\circ} \mathrm{C}$ overnight. TPP activated grafts were reacted with $1 \mathrm{mg} / \mathrm{mL}$ tetramethylrhodamine-5-carbonyl azide (Invitrogen, Carlsbad) in 1:4 tert-butanol/PBS at $37^{\circ} \mathrm{C}$ for $24 \mathrm{~h}$ followed by rinsing in methanol for $24 \mathrm{~h}$, or reacted with $20 \mu \mathrm{M} \mathrm{TM}-\mathrm{N}_{3}$ in PBS at $37^{\circ} \mathrm{C}$ for $24 \mathrm{~h}$ and rinsed with PBS for $24 \mathrm{~h}$. Grafts coated with PU and activated with TPP were reacted with rhodamine B or TM-methionine as controls.

Modification of Polyurethane Films: Thin clear PU films were solvent cast by drying $12.5 \% \mathrm{w} / \mathrm{v}$ Elasthane $80 \mathrm{~A}$ in DMF for $24 \mathrm{~h}$ at $60^{\circ} \mathrm{C}$ under vacuum. Films were subjected to isocyanate, TPP, and rhodamine reactions in a glass vial using identical conditions as graft substrates, 


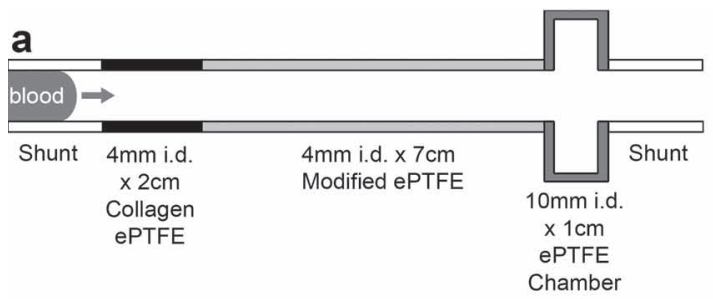

C

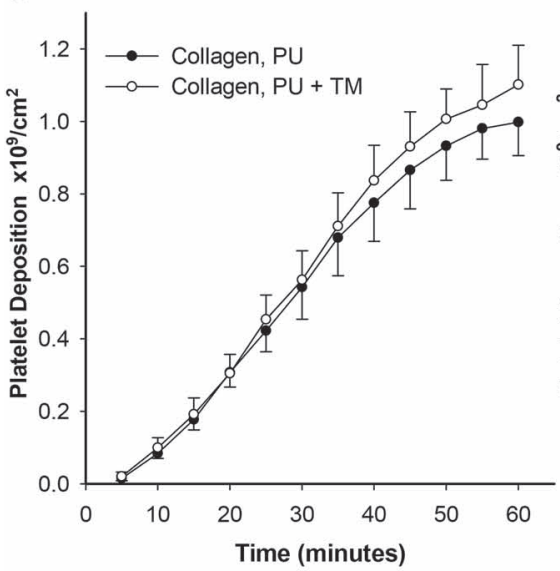

d
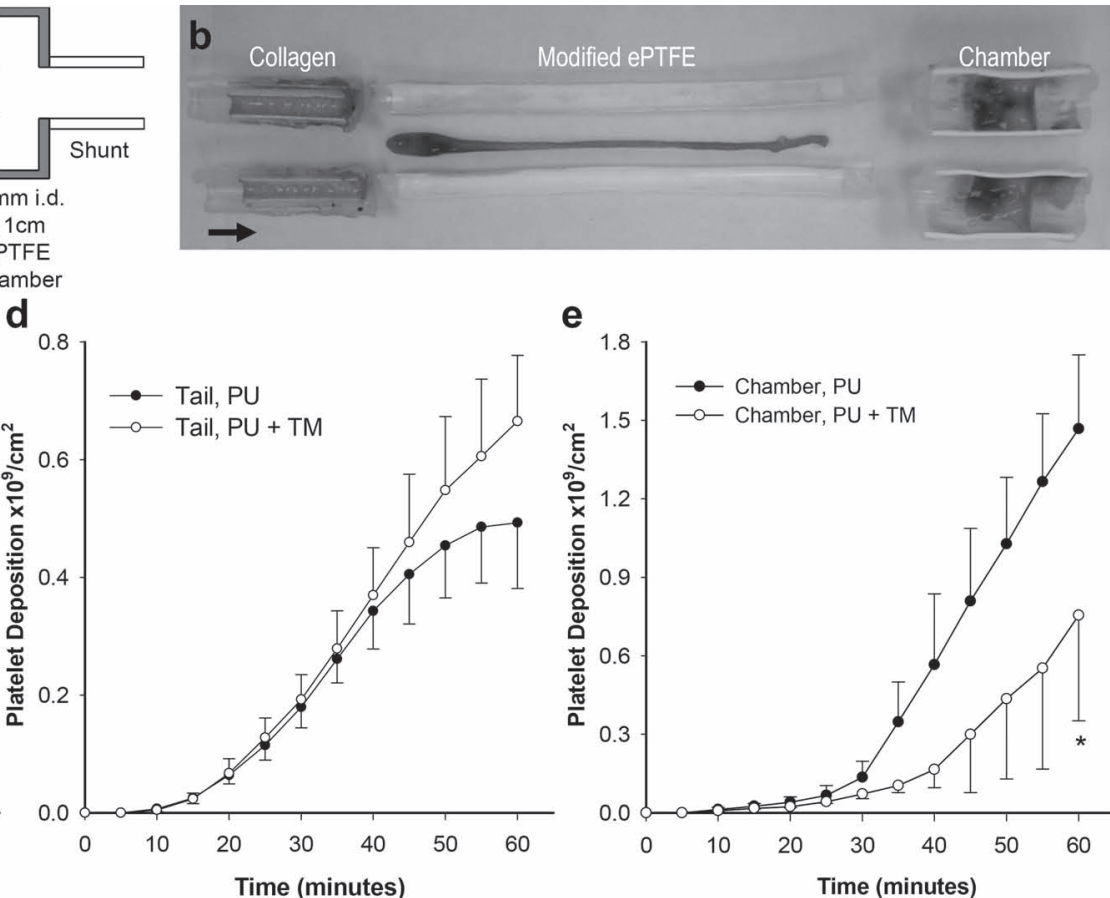

e

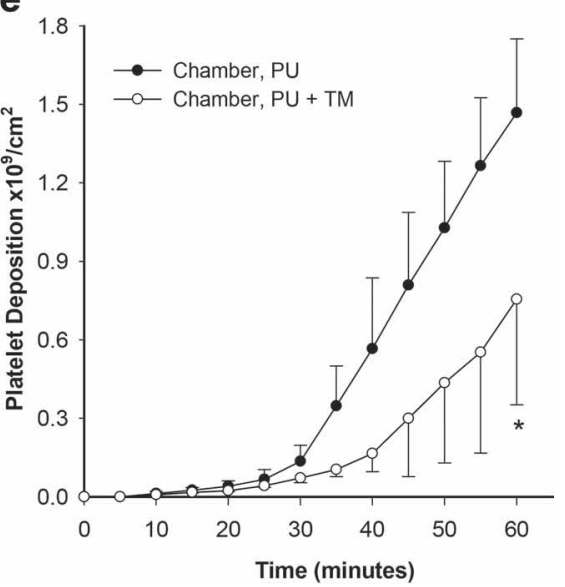

Figure 9. The biological function of TM modified ePTFE grafts was evaluated using a three-compartment thrombogenic device inserted into chronic arteriovenous shunts in baboons. (a) A $2 \mathrm{~cm} \times 4 \mathrm{~mm}$ inner diameter (i.d.) segment of collagen coated ePTFE serving as a thrombin source was connected upstream of a $7 \mathrm{~cm} \times 4 \mathrm{~mm}$ i.d. segment of test graft, and the therapeutic function of aPC generated in situ was detected in a $1 \mathrm{~cm} \times 10 \mathrm{~mm}$ i.d. distal expansion chamber. Arrow points in direction of blood flow. (b) Representative photograph of the entire chamber assembly that tested a $7 \mathrm{~cm}$ TM modified ePTFE graft split in half lengthwise following perfusion for $1 \mathrm{~h}$ at $100 \mathrm{~mL} / \mathrm{min}$. Arrow points in direction of blood flow. Real-time platelet deposition (c) in the upstream collagen coated $4 \mathrm{~mm}$ i.d. ePTFE segment; (d) in the thrombus tail developing distal to collagen coated ePTFE; and (e) in the $10 \mathrm{~mm}$ i.d. expansion chamber distal to TM modified ePTFE grafts (PU + TM) compared with bare PU coated ePTFE controls. Each data point represents mean \pm standard deviation of 4 independent studies. Statistical difference $(p<0.05)$ is denoted by single asterisk.

and characterized by UV-Vis spectroscopy (Cary 50 Bio UV-visible spectrophotometer, Varian).

Surface Analysis: An in-lens field-emission SEM (ISI DS-130F Schottky Field Emission SEM) operated at $10 \mathrm{kV}$ was used to examine the graft luminal surface. Light microscopy images of serial thin sections of modified grafts were used to determine PU thickness. ATR-IR spectra were acquired using a FTS-4000 FT-IR spectrometer (Bio-Rad, Hercules) equipped with a wide-band MCT detector, collected with 100 scans at $2 \mathrm{~cm}^{-1}$ resolution. XPS data were recorded on an Axis Ultra X-ray photoelectron spectrometer (Kratos Analyticals, UK) equipped with a monochromatized Al K $\alpha \mathrm{X}$-ray source.

TM Graft Cofactor Activity Assay: A $4 \mathrm{~mm}$ graft segment was incubated in $200 \mu \mathrm{L}$ of $0.2 \mu \mathrm{M}$ human protein $C$ (Calbiochem, Gibbstown), $5 \mathrm{mM}$ calcium chloride, and $2 \mathrm{nM}$ human $\alpha$-thrombin (Haematologic Technologies, Essex Junction) in Tris buffer (20 mM Tris, $100 \mathrm{mM} \mathrm{NaCl}$, $\mathrm{pH} 7.5$ ) with $0.1 \%$ bovine serum albumin (BSA) at $37{ }^{\circ} \mathrm{C}$ for $1 \mathrm{~h}$, and quenched with $2 \mathrm{IU} / \mathrm{mL}$ human anti-thrombin III (American Diagnostica, Stamford) for $5 \mathrm{~min}$. The generation of aPC was quantified using $0.2 \mathrm{mM}$ of an enzymatically digestible chromogenic substrate, Spectrozyme PCa (American Diagnostica). TM activity was assayed after grafts were exposed for $24 \mathrm{~h}$ to PBS at $37^{\circ} \mathrm{C}$ and $500 \mathrm{~s}^{-1}$ shear, as well as after incubation in PBS with $0.02 \%$ sodium azide at $37^{\circ} \mathrm{C}$ over a two week period.

Determination of TM Surface Density: All assay reactions were run in a 96-well plate, per manufacturer's instructions (American Diagnostica, Stamford). Moles of $\mathrm{EGF}_{5-6}$ domains bound to test grafts were calculated by a standard curve generated by ELISA using known concentrations of TM. At the end of each assay, graft segments were flattened between glass slides and scanned at $600 \mathrm{dpi}$ using a HP Scanjet $5370 \mathrm{C}$ scanner and the reactive area of each test sample was measured using Image] software.

In Vivo Baboon Arteriovenous Shunt Model: A chronic exteriorized arteriovenous shunt was implanted in male baboons, as previously described. ${ }^{[49,52]}$ All studies were approved by the Institutional Animal Care and Use Committee at Oregon Health and Science University. Mean blood flow rate through the shunt was measured continuously using a Doppler ultrasonic flow meter and held constant by an external screw clamp at $100 \mathrm{~mL} / \mathrm{min}$. Autologous platelets were radiolabeled one day prior to shunt study with Indium-111 oxine and re-injected into the baboon. Platelet deposition in the individual compartments of the shunt assembly was measured over a 60-minute perfusion period using a high sensitivity 99Tc collimator and scintillation camera (GE 400T, General Electric) imaging of the $172 \mathrm{keV}{ }^{111} \mathrm{In}$ g photon peak at 5-min intervals. ${ }^{[52]}$

Statistical Analysis: Two-tailed student's t-test assuming unequal variances was used to test for statistical significance between the means of two groups.

\section{Acknowledgements}

This work was supported by grants from the National Institute of Health.

Received: July 22, 2011

Revised: August 15, 2011

Published online: September 26, 2011 
[1] Y. Ikada, Biomaterials 1994, 15, 725.

[2] A. E. Nel, L. Madler, D. Velegol, T. Xia, E. M. V. Hoek, P. Somasundaran, F. Klaessig, V. Castranova, M. Thompson, Nat. Mater. 2009, 8, 543.

[3] B. D. Ratner, Biomaterials 2007, 28, 5144.

[4] S. W. Jordan, E. L. Chaikof, J. Vasc. Surg. 2007, 45 Suppl A, A104.

[5] M. B. Gorbet, M. V. Sefton, Biomaterials 2004, 25, 5681.

[6] B. Furie, B. C. Furie, N. Engl. J. Med. 2008, 359, 938.

[7] Z. Qu, E. L. Chaikof, Curr. Opin. Immunol. 2010, 22, 634.

[8] J. M. Anderson, A. Rodriguez, D. T. Chang, Semin. Immunol. 2008, 20, 86.

[9] V. L. Gott, J. D. Whiffen, R. C. Dutton, Science 1963, 142, 1297.

[10] A. I. de Agostini, S. C. Watkins, H. S. Slayter, H. Youssoufian, R. D. Rosenberg, J. Cell Biol. 1990, 111, 1293.

[11] P. C. Liaw, D. L. Becker, A. R. Stafford, J. C. Fredenburgh, J. I. Weitz, J. Biol. Chem. 2001, 276, 20959.

[12] M. D. Phaneuf, S. A. Berceli, M. J. Bide, W. C. Quist, F. W. LoGerfo, Biomaterials 1997, 18, 755.

[13] B. Seifert, P. Romaniuk, T. Groth, Biomaterials 1997, 18, 1495.

[14] J. Lahann, D. Klee, W. Pluester, H. Hoecker, Biomaterials 2001, 22, 817.

[15] C. K. Hashi, N. Derugin, R. R. Janairo, R. Lee, D. Schultz, J. Lotz, S. Li, Arterioscler. Thromb. Vasc. Biol. 2010, 30, 1621.

[16] S. C. Freitas, M. A. Barbosa, M. C. Martins, Biomaterials 2010, 31, 3772.

[17] Y. Ito, L. S. Liu, R. Matsuo, Y. Imanishi, J. Biomed. Mater. Res. 1992, 26, 1065.

[18] C. Salvagnini, S. Gharbi, T. Boxus, J. Marchand-Brynaert, Eur. J. Med. Chem. 2007, 42, 37.

[19] M. F. Gouzy, C. Sperling, K. Salchert, T. Pompe, U. Streller, P. Uhlmann, C. Rauwolf, F. Simon, F. Bohme, B. Voit, C. Werner, Biomaterials 2004, 25, 3493.

[20] C. T. Esmon, Biochim. Biophys. Acta 2000, 1477, 349.

[21] C. T. Esmon, J. Biol. Chem. 1989, 264, 4743.

[22] J. M. Goddard, J. H. Hotchkiss, Prog. Polym. Sci. 2007, 32, 698.

[23] A. Kishida, Y. Ueno, I. Maruyama, M. Akashi, Biomaterials 1994, 15, 1170.

[24] A. Kishida, Y. Ueno, I. Maruyama, M. Akashi, ASAIO J. 1994, 40, M840.

[25] C. Sperling, U. Konig, G. Hermel, C. Werner, M. Muller, F. Simon, K. Grundke, H. J. Jacobasch, V. N. Vasilets, Y. Ikada, J. Mater. Sci. Mater. Med. 1997, 8, 789.

[26] V. N. Vasilets, G. Hermel, U. Konig, C. Werner, M. Muller, F. Simon, K. Grundke, Y. Ikada, H. J. Jacobasch, Biomaterials 1997, 18, 1139.

[27] J. M. Li, M. J. Singh, P. R. Nelson, G. M. Hendricks, M. Itani, M. J. Rohrer, B. S. Cutler, J. Surg. Res. 2002, 105, 200.

[28] C. Sperling, K. Salchert, U. Streller, C. Werner, Biomaterials 2004, 25, 5101.

[29] B. Wu, B. Gerlitz, B. W. Grinnell, M. E. Meyerhoff, Biomaterials 2007, $28,4047$.
[30] H. Y. Yeh, J. C. Lin, J. Biomater. Sci. Polym. Ed. 2009, 20, 807.

[31] P. Jonkheijm, D. Weinrich, H. Schroder, C. M. Niemeyer H. Waldmann, Angew. Chem. Int. Ed. Engl. 2008, 47, 9618.

[32] E. M. Sletten, C. R. Bertozzi, Angew. Chem. Int. Ed. Engl. 2009, 48, 6974.

[33] A. Watzke, M. Kohn, M. Gutierrez-Rodriguez, R. Wacker H. Schroder, R. Breinbauer, J. Kuhlmann, K. Alexandrov, C. M. Niemeyer, R. S. Goody, H. Waldmann, Angew. Chem. Int. Ed. Engl. 2006, 45, 1408.

[34] J. Kalia, N. L. Abbott, R. T. Raines, Bioconjug. Chem. 2007, 18 1064.

[35] R. David, M. P. Richter, A. G. Beck-Sickinger, Eur. J. Biochem. 2004, $271,663$.

[36] K. Suzuki, H. Kusumoto, Y. Deyashiki, J. Nishioka, I. Maruyama, M. Zushi, S. Kawahara, G. Honda, S. Yamamoto, S. Horiguchi, EMBO J. 1987, 6, 1891

[37] M. B. Soellner, K. A. Dickson, B. L. Nilsson, R. T. Raines, J. Am Chem. Soc. 2003, 125, 11790.

[38] C. S. Cazalis, C. A. Haller, L. Sease-Cargo, E. L. Chaikof, Bioconjug. Chem. 2004, 15, 1005.

[39] J. F. Parkinson, M. Nagashima, I. Kuhn, J. Leonard, J. Morser, Biochem. Biophys. Res. Commun. 1992, 185, 567.

[40] K. L. Kiick, E. Saxon, D. A. Tirrell, C. R. Bertozzi, Proc. Natl. Acad. Sci. U. S. A. 2002, 99, 19

[41] T. R. Dargaville, G. A. George, D. J. T. Hill, A. K. Whittaker, Prog Polym. Sci. 2003, 28, 1355.

[42] D. Klee, H. Hocker, Polymers for biomedical applications: Improvement of the interface compatibility, Vol. 149, Springer-Verlag Berlin, Berlin 1999.

[43] N. M. K. Lamba, K. A. Woodhouse, S. L. Cooper, M. D. Lelah, Poly urethanes in biomedical applications, CRC Press, Boca Raton 1998.

[44] S. W. Jordan, K. M. Faucher, J. M. Caves, R. P. Apkarian, S. S. Rele, X. L. Sun, S. R. Hanson, E. L. Chaikof, Biomaterials 2006, 27, 3473.

[45] C. Freijlarsson, B. Wesslen, J. Appl. Polym. Sci. 1993, 50, 345.

[46] E. Saxon, J. I. Armstrong, C. R. Bertozzi, Org. Lett. 2000, 2, 2141.

[47] J. W. Weisel, C. Nagaswami, T. A. Young, D. R. Light, J. Biol. Chem. 1996, 271, 31485

[48] Y. Cadroy, J. M. Maraganore, S. R. Hanson, L. A. Harker, Proc. Natl. Acad. Sci. U. S. A. 1991, 88, 1177

[49] S. R. Hanson, J. H. Griffin, L. A. Harker, A. B. Kelly, C. T. Esmon, A. Gruber, J. Clin. Invest. 1993, 92, 2003.

[50] S. R. Hanson, K. S. Sakariassen, Am. Heart J. 1998, 135, S132.

[51] M. J. Byrom, P. G. Bannon, G. H. White, M. K. Ng, J. Vasc. Surg. 2010.

[52] S. W. Jordan, C. A. Haller, R. E. Sallach, R. P. Apkarian, S. R. Hanson, E. L. Chaikof, Biomaterials 2007, 28, 1191.

[53] C. A. McNamara, I. J. Sarembock, L. W. Gimple, J. W. Fenton, S. R. Coughlin, G. K. Owens, J. Clin. Invest. 1993, 91, 94.

[54] I. Chen, A. Y. Ting, Curr. Opin. Biotechnol. 2005, 16, 35.

[55] C. P. R. Hackenberger, D. Schwarzer, Angew. Chem. Int. Ed. Engl. 2008, 47, 10030. 